УДК 630*432(571.621)

\title{
КОМПЛЕКСНАЯ ОЦЕНКА ПОТЕНЦИАЛЬНОЙ ПРИРОДНОЙ ПОЖАРООПАСНОСТИ ОСУШЕННЫХ БОЛОТ НА ТЕРРИТОРИИ ЕВРЕЙСКОЙ АВТОНОМНОЙ ОБЛАСТИ
}

\author{
Зубарева Анна Михайловна', \\ anna-doroshenko@yandex.ru
}

\author{
Зубарев Виталий Александрович1, \\ Zubarev_1986@mail.ru \\ 1 Институт комплексного анализа региональных проблем ДВО РАН, \\ Россия, 679016, г. Биробиджан, ул. Шолом-Алейхема, 4.
}

\begin{abstract}
Актуальность исследования определяется необходимостью выявления наиболее пожароопасных территорий, подверженных влиянию осушения, которые могут являться основой для прогнозирования рисков возникновения пожаров, а также для разработки рекомендаций по рациональному использованию и снижению пожароопасности нарушенных земель Еврейской автономной области.

Цель: комплексная оценка потенциальной природной пожароопасности осушенных болот на территории Еврейской автономной области.

Методы. Для комплексной оценки потенциальной природной пожароопасности были выбраны критерии, которые являются средоформирующими в ландшафте для возникновения пожара: рельеф (угол наклона территории), климат (среднегодовое количество осадков и средняя многолетняя температура июля), внутренние воды (густота речной сети, уровень болотных вод), почвы (водопроницаемость и влагоёмкость почв) и растительность (класс пожароопасности растительности). Для оценки пожароопасности мелиоративных территорий из них были выбраны главные, поскольку такие показатели, как угол наклона и климатические условия, будут иметь одинаковое значение при исследованиях крупного масштаба. Каждый показатель оценен по равномерным пятиуровневым шкалам. Комплексная оценка была получена суммированием баллов.

Результаты. Была проведена оценка, учитывающая ряд основных природных фракторов, обуславливающих возникновение пожаров в пределах заболоченных территорий. Выделены территории с разной степенью природной предрасположенности к возникновению и распространению возгораний. Установлено, что осушительная мелиорация является одним из сельскохозяйственных факторов, способствующих возникновению пожаров растительности. Изменение режима увлажнения в первую очередь порождает трансформацию растительного покрова, где один тип растительности меняется на другой, а также изменение почвенного покрова и снижение уровня болотных вод. Это всё приводит к тому, что класс пожарной опасности территории в совокупности и покомпонентно сдвигается в сторону увеличения пожароопасности.
\end{abstract}

\section{Ключевые слова:}

Природный пожар, осушительная мелиорация, комплексная оценка, растительность, уровень болотных вод.

\section{Введение}

Одними из самых распространенных и опасных природных рисков являются природные пожары (ПП) [1-4]. ПП - это сложный объект исследования, который зависит от многообразия факторов: погодных и климатических условий $[5,6]$, характеристик растительного покрова [7], почв [8, 9], рельефа местности [10], а также влияния человека [11] и интенсивности техногенной нагрузки $[12,13]$. Вследствие осушительных работ изменяются пирологические свойства геосистем [14]: трансформируется накопление органических веществ [15], наблюдаются потери запасов углерода [16], изменяется рост растений [17-20], микроклимат [21], изменяется структура и состав почвы [22], изменяется уровень грунтовых вод [23].

Пожароопасность (ПО) территории определяется как угроза возникновения пожара, выражаемая его вероятностью, появлением факторов, обусловливающих пожар, а также их пирологическими характеристиками на определённой территории [24]. Факторы пожароопасности подразделяются на природные и антропогенные, в связи с этим вероятность появления природных факторов, определяющих появление и распространение пожара, а также природных пирологических характеристик на определённой территории, мы понимаем как природную пожароопасность. В качестве единицы оценки, дающей информацию о генетической взаимосвязи и взаимозависимости структурных частей природного происхождения и их пирологических свойств, был выбран бассейн реки [25].

Земли, изменённые человеком, как правило, менее устойчивы, чем те первичные, которые не были подвержены изменениям, ибо естественный механизм саморегуляции в них нарушен [26]. Поэтому некоторые экстремальные отклонения параметров внешней среды, которые снижены в естественных условиях, могут оказаться катастрофическими для территории, подверженной антропогенному воздействию мелиорации [27].

Проблемой пожароопасности водно-болотных угодий занимаются учёные разных стран. В Восточной и Юго-Восточной Азии по данным спутниковых данных MODIS больше всего пожарам подвержены водноболотные угодья в Индии, Пакистане, Индонезии и Мьянме, и на тридцати процентах территории ЮгоВосточной Азии пожары имеют тенденцию к повторению, больше всего в Лаосе, Камбодже, Таиланде и Мьянме. [28]. В подверженной пожарам восточной канадской тайге используют протяженность пожара и систематически реконструируют пространственно- 
временную изменчивость масштабов и интервалов пожаров, определяющих эталонные условия для оценки значимости, прогнозирования пространственновременной динамики и воздействия усиливающейся в настоящее время пожарной активности в североамериканских бореальных лесах [29]. В Китае установлена сезонная динамика выбросов метана в водно-болотных угодьях после пожаров [30]. В южной Амазонке периодические пожары привели к изменению видового состава и почвенного покрова, т. к. увеличилось количество голой земли и как следствие, уменьшилось видовое богатство и разнообразие видов. [31]. В Индонезии установили, что плантации масличных пальм и мелкие фермерские хозяйства возле населенных пунктов являются основными источниками пожаров в торфяноболотном лесном массиве в Центральном Калимантане [32], в Танзании изучают ретроспективу многолетних изменений растительности в результате пожаров на высокогорных водно-болотных угодьях на Килиманджаро [33]. Степень изученности вопроса по направлению пирологической уязвимости мелиорированных территорий в России не высока, работы проводились в Томской [34] и Ленинградской [35] областях. На Дальнем Востоке, несмотря на наличие осушенных заболоченных земель, исследования по влиянию на пожаро- опасность территории не проводились. В Еврейской автономной области, расположенной на юге Дальнего Востока, в данный момент больший сегмент мелиорированных земель по существу не эксплуатируется, обрастает мелколесьем и кустарниками и при низком уровне болотных вод периодически подвержен пожарам. Таким образом, целью данного исследования является проведение комплексной оценки (совокупности основных пожароопределющих факторов) потенциальной природной пожароопасности осушенных болот на территории ЕАО.

\section{Материалы и методики исследования}

Оценки ПО осушенной территории проведена на основе собственных данных полевых ландшафтных исследований, проведенных в 2008-2016 гг. Оценка ПО заболоченной территории в период до осушения проведена на основе имеющегося архивного картографического материала [36].

В качестве объектов исследования были выбраны три заболоченные территории, расположенные на территории Среднеамурской аллювиальной низменности, которые были осушены в 50-х гг. ХХ в. и до настоящего времени эксплуатируются как сельскохозяйственные пахотные угодья [37] (рис. 1).

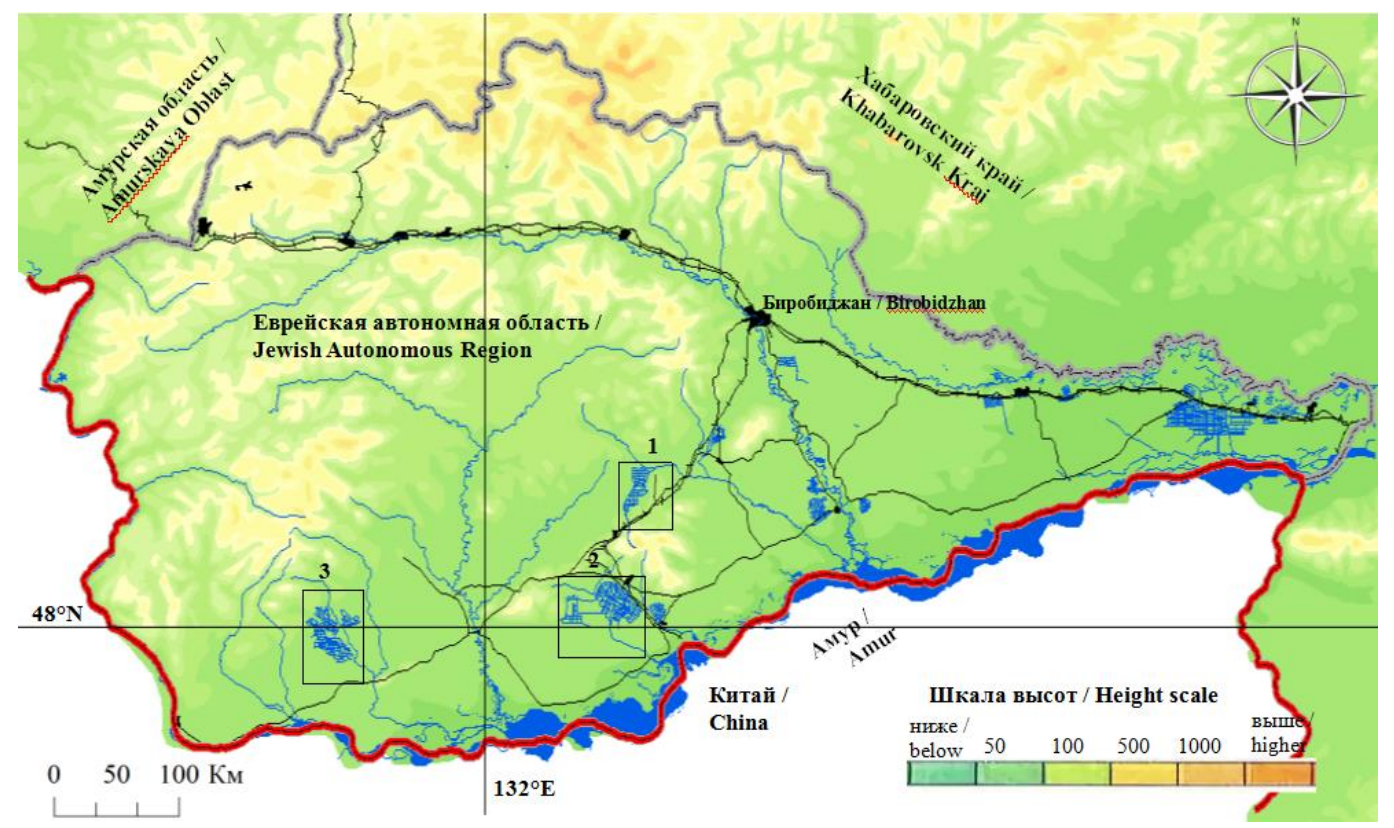

Рис. 1. Схема расположения объектов исследования

Fig. 1. Layout of the objects of study

Ландшафтные исследования выполнены на выбранных полигонах и включают в себя описание микрорельефа, растительности, уровня болотных вод (УБВ) [38, 39].

Е.С. Арцыбашевым разработана шкала природной пожарной опасности осушаемых лесных земель. В этой шкале автор предлагает по степени природной ПО, то есть предрасположенности к появлению огня, мелиорированные территории разделить на пять классов [40]. Предложенное распределение местности достойно высокого признания, но на наш взгляд не учитывает очень важные показатели, такие как уровень болотных вод и тип почв, которые обуславливают готовность к воспламенению растительных горючих материалов.

Средоформирующими критериями возникновение пожара являются: рельеф (угол наклона территории) [41], климат (среднегодовое количество осадков и средняя многолетняя температура июля) [42, 43], внутренние воды (густота речной сети, уровень болотных вод) [44], почвы (влагопроницаемость и влагоёмкость) $[45,46]$ и растительные сообщества (класс 
пожарной опасности растительности) [47], а также доля осушенной территорий.

Для данного анализа ПО осушенной местности из представленных критериев были выбраны главные: пожароопасность растительности, свойства почв, уровень болотных вод, поскольку такие показатели, как угол наклона и климатические характеристики, будут иметь одинаковое значение при исследованиях крупного масштаба.

Для покомпонентной оценки ПО осушенной территории использовались разработанные ранее методики. Класс пожарной опасности растительности определяется по методике Стародумова [47]. В этой классификации дальневосточные растительные сообщества разделены на пять классов по степени пожарной опасности. I класс характеризуется очень высокой пожарной опасностью, преобладанием массовых пожаров в пожароопасный период и верхних пожаров в засушливые периоды. Иногда пожар может возникнуть при низком значении показателя пожарной опасности Нестерова. V класс отличается очень низкой пожарной опасностью, с преобладанием пожаров только после продолжительной засухи. Эффектными инструментами для обработки и анализа полученных данных служат геоинформационные системы и технологии [48]. В связи с этим площадь исследуемых растительных формаций вычислялась на основе ее распределения в ГИС, созданной в MapInfo Professional 6.0 сотрудниками Лаборатории региональных геоэкологических исследований ИКАРП ДВО РАН). Исследования пожароопасности почв проводились, учитывая влагопроницаемость и влагоёмкость, поскольку эти свойства почв формируют условия увлажнения растительных горючих материалов. Используя разработанную нами ранее шкалу [44] по влагопропускной способности, типы почвы были разделены на пять классов и оценены от 1 до 5 баллов: наиболее проницаемые, невлагоёмкие почвы соответствуют 5 баллам, а труднопроницаемые, влагоёмкие 1 баллу. Данные по уровню болотных вод сформированы в результате полевых исследований, а пирологическая их оценка происходила в соответствии с классификацией в работе [34], где наиболее пожароопасным является УБВ ниже поверхности и соответствует 2 баллам, а наименее - выше поверхности (0 баллов) (таблица).

Каждый показатель оценен по соответствующей ему шкале, где максимальный балл присвоен наиболее пожароопасному значению. Комплексная оценка была получена суммированием баллов. Применение балльной оценки объясняется одновременным использованием критериев, имеющих количественные и качественные характеристики, к которым статистические методы не применяются. В балльной системе оценок многие авторы видят всеобщее средство измерения и установления связи различных индивидуальных оценок [49, 50]. Весовые коэффициенты, определяющие вклад каждого критерия в пожароопасность территории, не использовались вследствие разнообразия условий и комплексности разных факторов, формирующих пирологические условия, в том числе и недостаточной изученности физикохимических течений, возникающих при возгораниях.

\section{Результаты и их обсуждение}

Проведена оценка ПО бассейнов рек, подверженных осушению.

В анализе потенциальной природной ПО бассейнов исследуемых рек учет пирологических характеристик растительности весьма необходим, так как биота является непосредственным объектом горения [51]. Территория ЕАО отличается разнообразием растительности, неоднородность которой связана с широтной и высотной зональностью, присутствием интразональных группировок, антропогенным воздействием. Вследствие этого растительность изучаемой территории классифицирована в соответствии с пятью классами пожароопасности, каждый из которых был оценен в баллах; наименее пожароопасному присвоен 1 балл, а наиболее пожароопасному - 5. Установлено, что на исследуемой мелиорируемой территории растительные формации I класса - очень высокой ПО (5 баллов), занимают $37 \%$, к ним относятся осоково-разнотравно-вейниковые и вейниковые луга. Растительные формации высокой ПО (II класс), с пожароопасностью 4 балла, характеризуются дубняками и редколесьями с березой даурской, леспедецей двуцветной и лещиной разнолистной, а также травяными и кустарничково-травяными редколесьями, занимающими 12,5 \% от общей площади исследуемой мелиорируемой территории. Растительные формации со средним (III) классом ПО не были выделены. Низким (IV) значением рассматриваемого показателя (2 балла) обладают: смешенные широколиственные леса с преобладанием липы, участием мелколиственных пород, осиново-белоберезовые травянистые леса по рёлкам, местами в сочетании с ерниковотальничковыми зарослями и вейниково-осоковыми кочковатыми лугами. Они распространены на 12,8 \% площади. K V классу, с очень низкой пожароопасностью, относятся: комплекс осоково-разнотравновейниковых лугов, моховых и осоковых болот, с остатками лиственничных марей; лесные комплексы с дубняками, березняками и осинниками с разнотравновейниковыми лугами; мокрые вейнико-осоковые луга в сочетании с осоковыми и моховыми болотами, с редким ерником, единичной березой маньчжурской и осиной; прирусловые заросли ив, совместно занимающие всего менее 37,7 \% площади исследуемой области.

Таким образом, на исследуемой осушенной территории растительность наиболее опасных классов пожарной опасности составляют более 39,5 \%, что указывает на высокую пожароопасность территории.

Изучение пирологических свойств педосферы базируется на исследовании дренажных свойств почв, формировании благоприятных или неблагоприятных условий для возникновения возгораний. Влагопроницаемость (качество держать и процеживать воду) и влагоемкость (свойство задерживать то или иное количество воды) в педосфере определяют режим влагосодержания растительных горючих материалов и применяются в качестве критериев условий возгорания. При 
оценке пирологических свойств почв на осушенных землях было установлено, что территорий с почвами очень высокого (I) и высокого (III) класса пожарной опасности не обнаружено. Участки со II классом пожарной опасности составляют $15,3 \%$. К ним относятся бурые лесные почвы. Территории с почвами IV класса пожарной опасности занимают 41,9 \% оцениваемых земель, на которых расположены лугово-глеевые почвы. К V классу относятся лугово-болотные, болотнонизинные, лугово-бурые почвы, которые распространены на 42,8 \% исследуемой территории.
В таблице и на рисунках отражёны данные предрасположенности исследуемых территорий к возгоранию до и вовремя осушения, что позволяет проследить взаимосвязь природных компонентов и их пирогенных характеристик в рамках естественных границ речных бассейнов.

Бассейн р. Ульдура имеет площадь водосбора 8,5 тыс. га, на 1,1 тыс. га занят сельскохозяйственными землями, залесенность составляет $20 \%$, заболоченность - $80 \%$. Преобладающим типом растительности являются лугово-болотные луга с дерново-подзолистым типом почв.

Таблица. Оценка потенциальной природной ПО бассейна р. Ульдура

Table. Assessment of the potential natural fire hazard of the Uldur river basin

\begin{tabular}{|c|c|c|c|c|}
\hline & $\begin{array}{l}\text { Почвы (балы) } \\
\text { Soils (points) }\end{array}$ & $\begin{array}{l}\text { Растительность (баллы) } \\
\text { Vegetation (points) }\end{array}$ & $\begin{array}{c}\text { Уровень болотных } \\
\text { вод (балы) } \\
\text { Level of marsh } \\
\text { water (points) } \\
\end{array}$ & $\begin{array}{l}\text { Итог. } \\
\text { балл } \\
\text { Total } \\
\text { points } \\
\end{array}$ \\
\hline \multirow{6}{*}{ 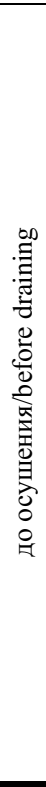 } & \multirow[b]{2}{*}{$\begin{array}{l}\text { Бурые } \\
\text { лесные суглинистые } \\
\text { Brown } \\
\text { forest loamy (3) }\end{array}$} & $\begin{array}{l}\text { Смешенные широколиственные леса с преобладанием липы } \\
\text { Mixed deciduous forests with a predominance of lime tree (4) }\end{array}$ & \multirow[b]{2}{*}{$\begin{array}{l}\text { Ниже поверхности } \\
\text { Below the surface } \\
\text { (2) }\end{array}$} & \multirow{6}{*}{22} \\
\hline & & $\begin{array}{l}\text { Дубняки и редколесья с березой даурской, леспедецей двуцвет- } \\
\text { ной и лещиной разнолистной } \\
\text { Oak forests and woodlands with Daurian birch, Lespedetsa bicolor } \\
\text { and variegated hazel (4) }\end{array}$ & & \\
\hline & \multirow{4}{*}{$\begin{array}{l}\text { Луговые глинистые } \\
\text { Clayey meadow (2) }\end{array}$} & $\begin{array}{l}\text { Мокрые вейнико-осоковые луга в комплексе с осоковыми и мохо- } \\
\text { выми болотами, иногда с редким ерником, единичной березой } \\
\text { маньчжурской } \\
\text { Wet reed grass-sedge meadows in a complex with sedge and moss } \\
\text { bogs, sometimes with rare dwarf birch, single Manchurian birch (1) }\end{array}$ & \multirow{2}{*}{$\begin{array}{l}\text { На уровне } \\
\text { поверхности } \\
\text { Surface level (1) }\end{array}$} & \\
\hline & & $\begin{array}{l}\text { Осоково-разнотравно-вейниковые и вейниковые луга, переодиче- } \\
\text { ски или постоянно переувлажненные } \\
\text { Sedge-forb-reed grass and reed grass meadows, periodically or perma- } \\
\text { nently waterlogged (1) }\end{array}$ & & \\
\hline & & $\begin{array}{l}\text { Осиново-белоберезовые травянистые леса по релкам, местами в } \\
\text { сочетании с ерниково-тальничковыми зарослями и вейниково- } \\
\text { осоковыми кочков } \\
\text { Aspen-white birch herbaceous forests along reeds, in places in combi- } \\
\text { nation with dwarf birch-talnik thickets and reed-sedge hummocks (2) }\end{array}$ & \multirow{2}{*}{$\begin{array}{l}\text { Выше уровня } \\
\text { поверхности } \\
\text { Above the surface } \\
\text { level (0) }\end{array}$} & \\
\hline & & $\begin{array}{l}\text { Редколесье осины и маньчжурской березы с ивой козьей и вей- } \\
\text { никово-осоковыми лугами } \\
\text { Sparse forests of aspen and Manchurian birch with goat willow and } \\
\text { reed-sedge meadows (2) }\end{array}$ & & \\
\hline \multirow{7}{*}{ 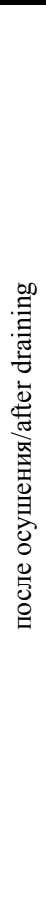 } & \multirow[b]{2}{*}{$\begin{array}{l}\text { Бурые } \\
\text { лесные суглинистые } \\
\text { Brown forest loamy (3) }\end{array}$} & $\begin{array}{l}\text { Смешенные широколиственные леса с преобладанием липы } \\
\text { Mixed deciduous forests dominated by linden (4) }\end{array}$ & \multirow[b]{2}{*}{$\begin{array}{l}\text { Ниже поверхности } \\
\text { Below the surface } \\
\text { (2) }\end{array}$} & \multirow{7}{*}{31} \\
\hline & & $\begin{array}{l}\text { Дубняки и редколесья с березой даурской, леспедецей двуцвет- } \\
\text { ной и лещиной разнолистной } \\
\text { Oak forests and woodlands with Daurian birch, Lespedetsa bicolor } \\
\text { and variegated hazel (4) }\end{array}$ & & \\
\hline & \multirow{4}{*}{$\begin{array}{l}\text { Луговые глинистые } \\
\text { Clayey } \\
\text { meadow (2) }\end{array}$} & $\begin{array}{l}\text { Мокрые вейнико-осоковые луга в комплексе с осоковыми и мо- } \\
\text { ховыми болотами, иногда с редким ерником, единичной березой } \\
\text { маньчжурской } \\
\text { Wet reed grass-sedge meadows in a complex with sedge and moss } \\
\text { bogs, sometimes with rare dwarf birch, single Manchurian birch (1) }\end{array}$ & \multirow{2}{*}{$\begin{array}{l}\text { На уровне } \\
\text { поверхности } \\
\text { Surface } \\
\text { level (1) }\end{array}$} & \\
\hline & & $\begin{array}{l}\text { Осоково-разнотравно-вейниковые и вейниковые луга, переоди- } \\
\text { чески или постоянно переувлажненные } \\
\text { Sedge-forb-reed and reed meadows, periodically or constantly water- } \\
\text { logged (1) }\end{array}$ & & \\
\hline & & $\begin{array}{l}\text { Осиново-белоберезовые травянистые леса по релкам, местами в } \\
\text { сочетании с ерниково-тальничковыми зарослями и вейниково- } \\
\text { осоковыми кочков } \\
\text { Aspen-white birch herbaceous forests along reeds, in places in combi- } \\
\text { nation with dwarf birch-talnik thickets and reed-sedge hummocks (2) }\end{array}$ & $\begin{array}{l}\text { Выше уровня } \\
\text { поверхности } \\
\text { Above the surface } \\
\text { level (0) }\end{array}$ & \\
\hline & & $\begin{array}{l}\text { Редколесье осины и маньчжурской березы с ивой козьей и вей- } \\
\text { никово-осоковыми лугами } \\
\text { Sparse forests of aspen and Manchurian birch with goat willow and } \\
\text { reed-sedge meadows (2) }\end{array}$ & $\begin{array}{l}\text { Ниже поверхности } \\
\text { Below the surface } \\
\text { (2) }\end{array}$ & \\
\hline & $\begin{array}{l}\text { Антропогенно преобразован- } \\
\text { ные сельскохозяйственные } \\
\text { Anthropogenically transformed } \\
\text { agricultural (2) }\end{array}$ & $\begin{array}{l}\text { Осушенные разнотравно-злаковые луга и сельскохозяйственные } \\
\text { посевные угодия } \\
\text { Drained forb-cereal meadows and agricultural crops (5) }\end{array}$ & $\begin{array}{l}\text { Ниже поверхности } \\
\text { Below the surface } \\
\text { (2) }\end{array}$ & \\
\hline
\end{tabular}


Бассейн р. Ульдура стал пожароопаснее по природным характеристикам (интегральный показатель изменился с 22 до 31) после проведения в его границах осушительных работ. Это связано с тем, что увеличивается, приблизительно в два раза, площадь земель с уровнем болотных вод ниже поверхности и растительностью, относящейся к I классу (очень высокой) пожароопасности.

Бассейн р. Грязнушка (рис. 2) был оценен по такому же принципу как бассейн р. Ульдура (таблица). Растительный и почвенный покров относительно однороден: 4,4 тыс. га (20 \%) занято бурыми почвами с лесной растительность и около 14,6 тыс. га (80 \%) приходится на луговые почвы с разнотравными лугами, периодически или постоянно переувлажненными. Общий итоговый балл ПО территории бассейна до проведения осушительных работ составляет 24.

После осушения и проведения сельскохозяйственных работ вероятность возникновения пожара возрастает (интегральный показатель баллов изменился с 24 до 27), так как повышается, приблизительно в два раза, площадь земель с уровнем болотных вод ниже поверхности и растительностью, относящейся к I классу (очень высокой) ПО.

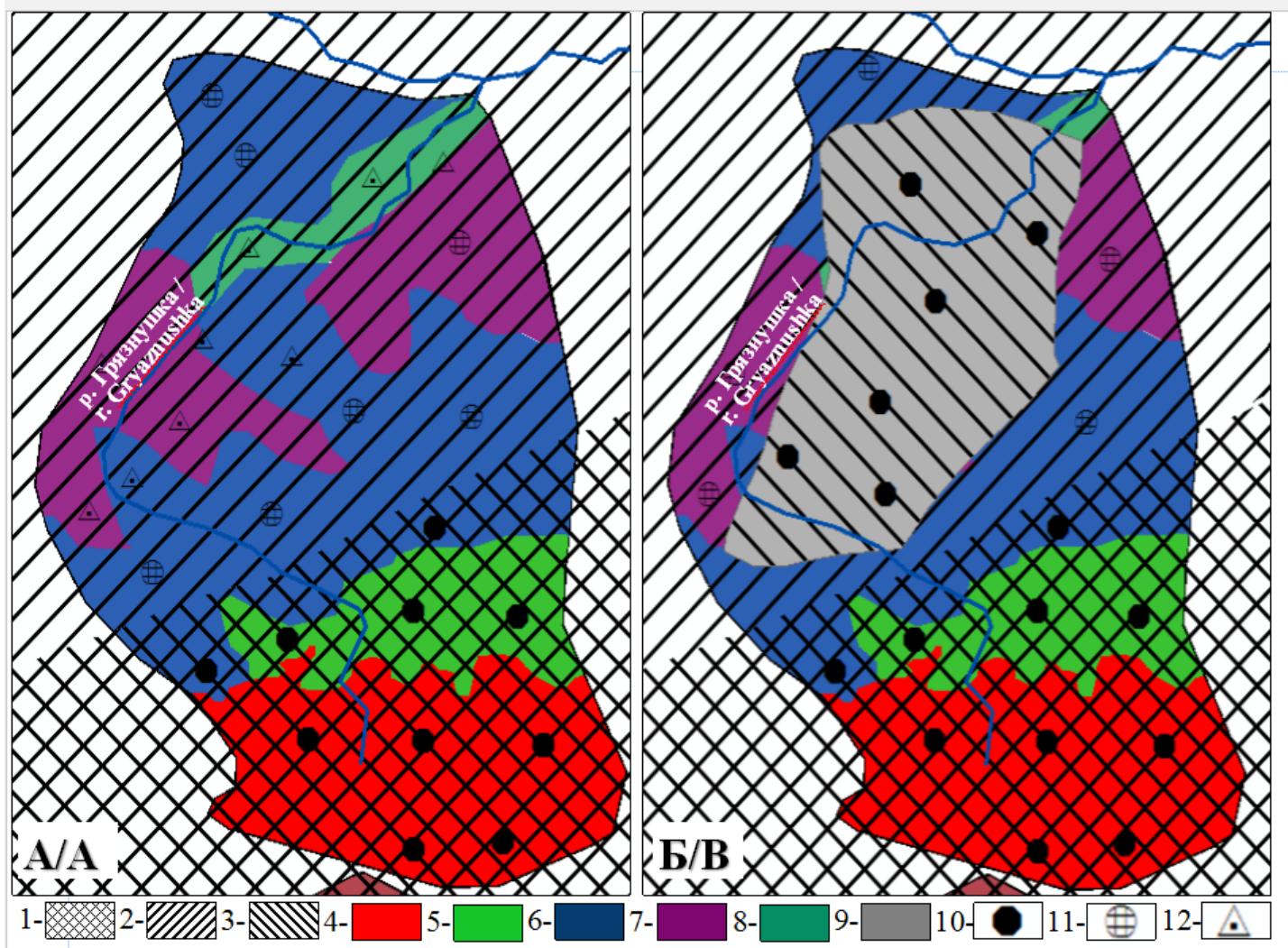

Pис. 2. Бассейн р. Грязнушка до (А) и после (Б) проведения осушительных работ. Условные обозначения. Почвы: 1 - бурые лесные, 2 - луговые глинистые, 3 - антропогенно-преобразованные сельскохозяйственные. Растительность: 4 - смешенные широколиственные леса с преобладанием липы, 5 - дубняки и редколесья с березой даурской, леспедецей двуцветной и лещиной разнолистной, 6 - осоково-разнотравно-вейниковые и вейниковые луга, периодически или постоянно переувлажненные, 7 - мокрые вейнико-осоковые луга в комплексе с осоковыми и моховыми болотами, иногда с редким ерником, еденичной березой маньчжурской, 8 - прирусловые заросли ив, 9 - осушенные разнотравно-злаковые луга и сельскохозяйственные посевные угодия. Уровень болотных вод: 10 - ниже уровня поверхности, 11 - на уровне поверхности, 12 - выше уровня поверхности

Fig. 2. Basin of the Gryaznushka river before (A) and after (B) drainage works. Symbols. Soils: 1 - brown forest, 2 - meadow clayey, 3 - anthropogenically transformed agricultural soils. Vegetation: 4 - mixed broad-leaved forests with a predominance of linden, 5 - Dubnyaki and light forests with Daurian birch, Lespedetsa bicolor and variegated hazel, 6 - sedge-forb-reed and reed meadows, periodically or constantly waterlogged, 7 - wet reed meadows in sedge complex with sedge and moss bogs, sometimes with rare dwarf birch, single Manchurian birch, 8 - riverbed willow thickets, 9 -drained forb-cereal meadows and agricultural crops. Bog water level: 10 - below surface level, 11 - at surface level, 12 - above surface level

По примеру р. Ульдура (таблица) была составлена оценка природной ПО р. Осиновка (рис. 3). Бассейн р. Осиновка имеет площадь водосбора 430 тыс. га. Залесенность ее бассейна составляет $30 \%$, заболоченность 70 \%. Водоток и всё его русло трансформировано в мелиоративный канал, бассейн занят лугами и пастбищами.
В нижнем течении долины реки высокий процент заболоченности. Здесь река принимает большое количество мелиоративных каналов. В среднем течении русло реки выпрямлено, сильно активно затягивается высшей водной растительностью, скорость течения низкая, русловой аллювий представлен преимущественно илом. 

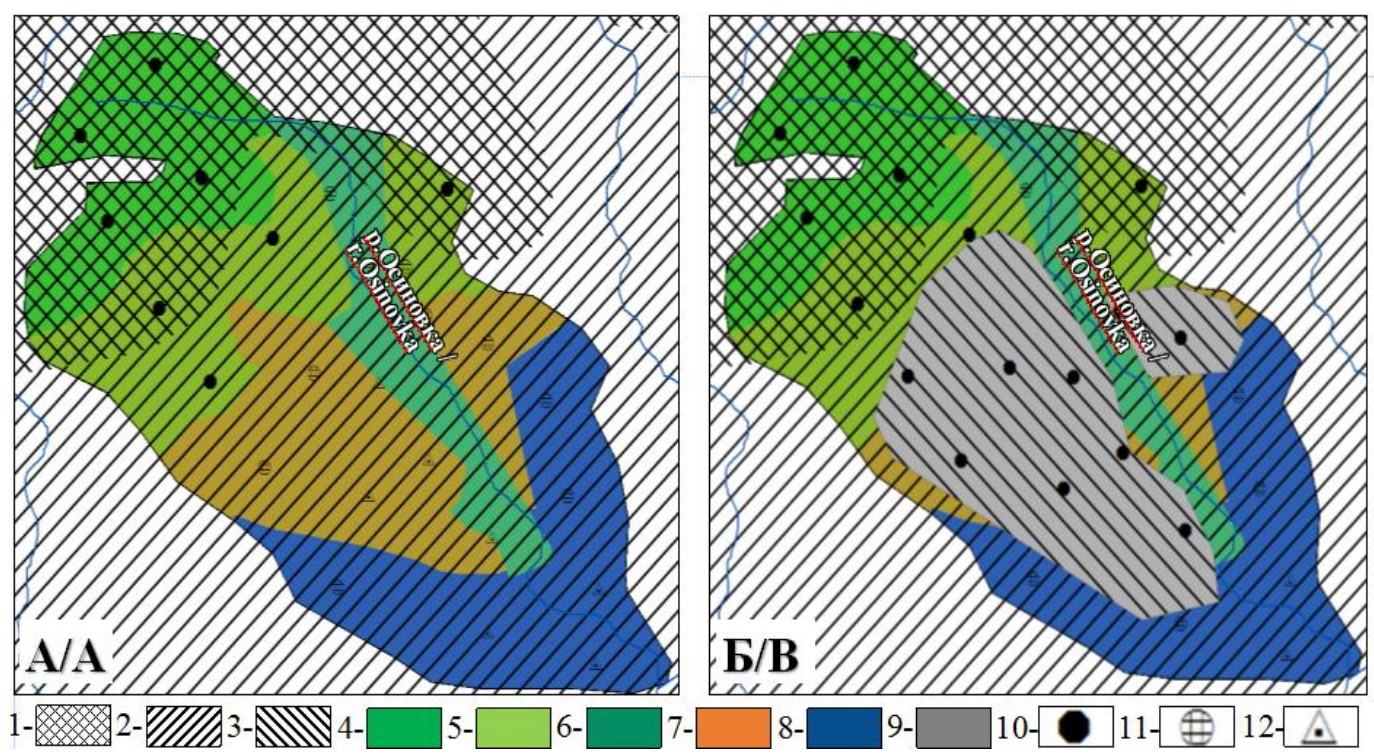

Рис. 3. Бассейн р. Осиновка до (А) и после (Б) проведения осушительных работ. Условные обозначения. Почвы: 1 - бурые лесные, 2 - луговые глинистые, 3 - антропогенно-преобразованные сельскохозяйственные. Растительность: 4 - дубняки и редколесья с березой даурской, леспедецей двуцветной и лещиной разнолистной, 5 - смешенные леса и редколесья с большим участием мелколиственных пород, 6 - прирусловые заросли ив, 7 - комплекс осоково-разнотравно-вейниковых лугов, моховых и осоковых болот, с остатками лиственничных марей, 8 - осоково-разнотравно-вейниковые и вейниковые луга, периодически или постоянно переувлажненные, 9 - осушенные разнотравно-злаковые луга и сельскохозяйственные посевные угодия. Уровень болотных вод: 10 - ниже уровня поверхности, 11 - на уровне поверхности, 12 - выше уровня поверхности

Fig. 3. Basin of the Osinovka river before $(A)$ and after (B) drainage works. Symbols. Soils: 1 - brown forest, 2 - meadow clayey, 3 - anthropogenically transformed agricultural soils. Vegetation: 4 - oak forests and light forests with Daurian birch, Lespedetsa bicolor and variegated hazel, 5 - mixed forests and light forests with a large participation of small-leaved species, 6 - riverbed willow thickets, 7 - complex of sedge-forb-reed meadows, moss and sedge bogs with remnants of larch marshes, 8 - sedge-forb-reed and reed meadows, periodically or permanently waterlogged, 9 - drained forb-cereal meadows and agricultural crops. Bog water level: 10 - below surface level, 11 - at surface level, 12 - above surface level

Оценивая природную пожароопасность бассейна реки Осиновка, можно заключить, что вероятность возникновения возгораний после проведения осушения увеличилась (интегральный показатель баллов изменился с 21 до 31), так как примерно в два раза увеличилась территория с уровнем болотных вод ниже поверхности и пожароопасной растительностью, относящейся к I классу - очень высокой пожарной опасности.

Таким образом, в ходе исследования пожарной опасности выбранных бассейнов рек можно заключить, что после осушения пожароопасность исследуемой территории увеличилась. Об этом свидетельствует итоговый балл комплексной оценки, который во всех случаях увеличивается после осушения. Это происходит вследствие:

- появления осушенных территорий. Часть территории с периодически или постоянно переувлажнёнными лугами заняли осушенные разнотравновейниковые и вейниковые луга. Трансформируемая территория составила 15,1 тыс. га.

- замены растительного покрова. Прирусловые заросли ив; комплекс осоково-разнотравно-вейниковых лугов, моховых и осоковых болот, с остатками лиственничных марей; осоково-разнотравновейниковые и вейниковые луга, периодически или постоянно переувлажненные, частично трансфор- мировались в осушенные разнотравно-вейниковые и вейниковые луга, а также сельскохозяйственные посевные угодия.

- снижения уровня болотных вод на 16,2 тыс. га исследуемой территории бассейнов рек, подверженных мелиорации.

- трансформации почвенного покрова, где типичные почвы изменяются в антропогенно-преобразованные сельскохозяйственные.

\section{Заключение}

Таким образом, была проведена пирологическая оценка в пределах заболоченных территорий с учётом ряда основных факторов, формирующих природные условия развития пожаров. Выделены бассейны с разной степенью природной предрасположенности к возникновению и распространению возгораний.

Осушительная мелиорация является одним из сельскохозяйственных факторов, способствующих возникновению пожаров растительности. Изменение режима увлажнения в первую очередь приводит к трансформации растительного покрова, где один тип растительности меняется на другой, изменению почвенного покрова, снижению уровня болотных вод. Это всё приводит к тому, что класс пожарной опасности территории в совокупности и покомпонентно сдвигается в сторону увеличения пожароопасности. 
Полученные результаты могут являться базой для прогнозирования природных возгораний, в том числе и разработки рекомендаций по целесообразному использованию и уменьшению потенциальной природной пожароопасности мелиорируемых территорий Еврейской автономной области.

\section{СПИСОК ЛИТЕРАТУРЫ}

1. Hallema D.W., Robinne F.-N., Bladon K.D. Reframing the challenge of global wildfire threats to clean water // Earth's Future. 2018. - V. 6. - № 6. - P. 772-776. DOI: 10.1029/2018EF000867.

2. Goldammer J.G. Regional climate change and forest fires // LargeArea Forest Fires. - Warsaw: Forest Research Institute, 2004. P. 5-8.

3. Goldammer J.G. Report on early warning for fire and other environmental hazards // UN International Decade for Natural Disaster Reduction. - Geneva: Freiburg University, 1997. - P. 3-34.

4. Fire spread from MODIS burned area data: obtaining fire dynamics information for every single fire International / D. Frantz M. Stellmes, A. Röder, J. Hill // Journal of Wildland Fire. 2016. - V. 25. - № 12. - P. 1228-1237. DOI: 10.1071/WF16003.

5. Bedel A., Mote T., Goodrick S. Climate change and associated fire potential for the south-eastern United States in the 21st Century // International Journal of Wildland Fire. - 2013. - V. 22. - P. 1034-1043. DOI: 10.1071/WF13018.

6. Сычев Р.С., Базаров А.В., Бадмаев Н.Б. Использование метеорологических данных Вега-SCIENCE для изучения различий в возникновении пожарной опасности в аридных и гумидных ландшафт Байкальского региона // Современные проблемы дистанционного зондирования Земли из космоса. - 2020. T. 17. - № 3. - C. 127-134

7. Kopoteva T.A., Kuptsova V.A. Effect of fires on the functioning of phytocenoses of peat bogs in the Middle-Amur lowland // Russian Journal of Ecology. - 2016. - T. 47. - № 1. - P. 11-18. DOI $10.7868 / \mathrm{S} 0367059715060086$.

8. Влияние лесных пожаров на свойства почв (обзор литературы) А.А. Дымов, Е.В. Абакумов, И.Н. Безкоровайная, А.С. Прокушкин, Я.В. Кузяков, Е.Ю. Милановский // Теоретическая и прикладная экология. - 2018. - № 4. - С. 13-23.

9. The effect of tropical peat land-use changes on plant diversity and soil properties / C. Agus, Z.R. Ilfana, F.F. Azmi, D. Rachmanadi, Widiyatno, D. Wulandari, P.B. Santosa, M.K. Harun, T.W. Yuwat T. Lestari // International Journal of Environmental Science and Technology. - 2020. - V. 17. - P. 1703-1712. DOI: 10.1007/s13762-019-02579-x.

10. Potential influence of nutrient availability along a hillslope: peatland gradient on aspen recovery following fire / M. Depante, R.M. Petrone, K.J. Devito, N. Kettridge, M.L. Macrae, C. Mendoza, J.M. Waddington // Ecohydrology. - 2018. - V. 11. - № 5. DOI: $10.1002 /$ eco.1955.

11. Human impacts on fire occurrence: a case study of hundred years of forest fires in a dry alpine valley in Switzerland / T. Zumbrunnen, P. Menéndez, H. Bugmann, M. Conedera, U. Gimmi, M. Bürgi // Regional Environmental Change. - 2012. - V. 12. № 4. - P. 935-949. DOI: 10.1007/s10113-012-0307-4

12. Peat swamp forest; management and development of indigenous species to support economic local people at periphery foret (case study in Central Borneo, Indonesia) / L. Indrayanti, J.M. Rotinsulu, Y. Yanarita, S. Sosilawaty // Journal of Ecological Engineering Received. - 2019. - V. 20. - № 4. - P. 76-83.

13. Sources of anthropogenic fire ignitions on the peat-swamp landscape in Kalimantan, Indonesia / M.E. Cattau, M.E. Harrison, I Shinyo, S. Tungau, M. Uriart, R. DeFries // Global Environmental Change. - 2019. - V. 39. - P. 205-219. DOI: 10.1016/j.gloenvcha.2016.05.005.

14. Pinno B.D., Hawkes V.C. Temporal trends of ecosystem development on different site types in reclaimed boreal forests // Forests. 2015. - V. 6. - № 6. - P. 2109-2124. DOI: 10.10.3390/f6062109.

15. Anderson J., Prescott C.E., Grayston S.J. Organic matter accumulation in reclaimed soils under spruce, poplar and grass in the Alberta Oil Sands // New Forests. - 2019. - V. 50. - P. 307-322. DOI: $10.1007 / \mathrm{s} 11056-018-9646-4$
Следует отметить, что данная работа на территории ЕАО является только начальным этапом в изучении условий возникновения и территориального распространения пожаров. В перспективе для комплексной оценки пожароопасности мелиорируемых земель необходимо учесть антропогенный фактор и фактическую горимость территории.

16. Carbon stocks of mangroves and losses arising from their conversion to cattle pastures in the Pantanos de Centla, Mexico / J.B. Kauffman, T.H. Hernandez, M. del Carmen Jesus Garcia, W.M. Contreras // Wetlands Ecology and Management. - 2016. V. 24. - P. 203-216. DOI: 10.1007/s11273-015-9453-z.

17. Loblolly pine growth patterns on reclaimed mineland: allometry, biomass, and volume / J. Priest, J. Stovall, D. Coble, B. Oswald, H. Williams // Forests. - 2015. - V. 6. - № 10. - P. 3547-3581. DOI: $10.3390 / f 6103547$

18. Tremblay P.Y., Thiffault E., Pinno B.D. Effects of land reclamation practices on the productivity of young trembling aspen and white spruce on a reclaimed oil sands mining site in northern Alberta // New Forests. - 2019. - V. 50. - P. 911-942. DOI: 10.1007/s11056-019-09705-0.

19. Gupta S.D., Pinno B.D. Spatial patterns and competition in trees in early successional reclaimed and natural boreal forests // Acta Oecologica. - 2018. - V. 92. - P. 138-147. DOI: 10.1016/j.actao.2018.05.003

20. Hydraulic redistribution and hydrological controls on aspen transpiration and establishment in peatlands following wildfire / M. Depante, M.Q. Morison, R.M. Petrone, K.J. Devito, N. Kettridge, J.M. Waddington // Hydrological Processes. 2019. - V. 33. - № 12. - P. 2714-2728. DOI: 10.1002/hyp.13522.

21. Watts A.C., Kobziar L.N. Hydrology and fire regulate edge influence on microclimate in wetland forest patches // Freshwater Science. 2015. - V. 34. - № 4. - P. 1383-1393. DOI: 10.1086/683534.

22. Sulwinski M., Metrak M., Suska-Malawska M. Long term fire effects of the drained open fen on organic soils // Archives of Environmental Protection. - 2017. - V. 43. - № 1. - P. 11-19. DOI: 10.1515/aep-2017-0002.

23. Begmatov I.A. Land meliorative status in irrigated lands of Syrdarya province // European Science Review. - 2017. - V. 1-2. P. $177-181$.

24. Курбатский Н.П. Терминология лесной пирологии // Вопросы лесной пирологии. - Красноярск: ИлиД, 1972. - С. 171-213.

25. Зубарев В.А. Изменение концентраций тяжелых металлов в компонентах малой реки (на примере осушительной мелиорации) // Известия Томского политехнического университета. Инжиниринг георесурсов. - 2020. - Т. 331. - № 8. - С. 16-23. DOI: $10.18799 / 24131830 / 2020 / 8 / 2764$.

26. Ecosystem scale evapotranspiration and $\mathrm{CO}_{2}$ exchange in burned and unburned peatlands: Implications for the ecohydrological resilience of carbon stocks to wildfire / M.Q. Morison, R.M. Petrone, S.L. Wilkinson, A. Green, J.M. Waddington // Ecohydrology. 2020. - V. 13. - № 2. - P. 2189. DOI: 10.1002/eco.2189.

27. Peatland-fire interactions: a review of wildland fire feedbacks and interactions in Canadian boreal peatlands / K. Nelson, D. Thompson, C. Hopkinson, R. Petrone, L. Chasmer // Science of the Total Environment. - 2021. - V. 769. - P. 145212. DOI: 10.1016/j.scitotenv.2021.145212

28. Trends in vegetation fires in south and southeast Asian countries / K.P. Vadrevu, K. Lasko, L. Giglio, W. Schroeder, S. Biswas, C. Justice // Scientific Reports. - 2019. - V. 9. - P. 7422. DOI: 10.1038/s41598-019-43940-x.

29. Spatial and temporal dimensions of fire activity in the fire-prone eastern Canadian taiga / S. Erni, D. Arseneault, M.A. Parisien, Y. Begin // Global Change Biology. - 2017. - V. 23. - № 3. P. 1152-1166. DOI: $10.1111 / \mathrm{gcb} .13461$.

30. Short-term effects of fire disturbance on $\mathrm{CH}_{4}$ emission from forested wetlands in the Xiaoxing'an Mountains, Northeast China / H. Gu, W. Zheng, D. Xu, C. Mu // Journal of Forestry Research. 2019. - V. 30. - P. 969-979. DOI: 10.1007/s11676-018-0774-7.

31. Vetrita Y., Cochrane M.A. Fire frequency and related land-use and land-cover changes in Indonesia's Peatlands // Remote Sens. 2020. - V. 12. - № 1. - P. 5-11. DOI: 10.3390/rs12010005. 
32. Fine-scale effects of fire on non-woody species in a southern Amazonian seasonal wetland / H.S. Jancoski, J.R.R. Pinto, D.S. Nogueira, H.A. Mews, J.S. Abad, M.C. Scalon, B.S. Marimon // Wetlands Ecology and Management. - 2019. - V. 27. P. 267-281. DOI: 10.1007/s11273-019-09658-3.

33. A 3000-year record of vegetation changes and fire at a highelevation wetland on Kilimanjaro, Tanzania / C.J.C. Mustaphi, R. Kinyanjui, A. Shoemaker, C. Mumbi, V. Muiruri, L. Marchant, S.M. Rucina, R. Marchant // Quaternary Research. - 2020. V. 99. - P. 34-62. DOI: doi.org/10.1017/qua.2020.76

34. Оценка потенциальной пожарной опасности осушенных болот Томской области / А.А. Синюткина, Е.Н. Бурнашова, А.А. Беленко, Л.П. Гашкова, А.А. Малолетко // Известия Томского политехнического университета. Инжиниринг георесурсов. 2015. - T. 326. - № 12. - C. 45-53.

35. Безпалько Р.В. Влияние осушения на природную пожарную опасность лесов: автореф. дис. ... канд. с.-х. наук. - СПб., 2004. $-27 \mathrm{c}$.

36. Куренцова Г.Э. Очерк растительности Еврейской автономной области. - Владивосток: Дальневост. кн. изд-во, 1967. - 61 с.

37. Зубарев В.А., Мищук С.Н. Изменение концентраций тяжелых металлов почв юга Среднеамурской низменности при длительном сельскохозяйственном использовании // Известия Томского политехнического университета. Инжиниринг георесурсов. - 2019. - Т. 330. - № 8. - C. 18-26. DOI: $10.18799 / 24131830 / 2019 / 8 / 2208$.

38. Zubarev V.A., Kogan R.M. Ecological conditions of watercourses in the Middle Amur Lowland in the areas of drainage reclamation // Water Resources. - 2017. - V. 44. - № 7. - P. 940-951.

39. Zubarev V.A., Mazhaysky Y.A., Guseva T.M. The impact of drainage reclamation on the components of agricultural landscapes of small rivers // Agronomy Research. - 2020. - V. 18. - № 4. P. 2677-2686.

40. Арцыбашев Е.С. Проблема пожаров на оторфованных лесных землях // Лесное хозяйство. - 2006. - № 5. - С. 36-38.

41. Шешуков М.А. Исследование природы низовых пожаров в основных лесных формациях Нижнего Приамурья: автореф. дис. ... канд. с.-Х. наук. - Красноярск, 1970. - 27 с.
42. Коган Р.М., Глаголев В.А. Система пространственного прогноза возникновения пожаров по погодным и лесорастительным условиям // Безопасность в техносфере. - 2013. - Т. 2. № 5. - C. 11-20.

43. Григорьева Е.А., Коган Р.М. Пирологические характеристики климата на юге Дальнего востока России // Региональные проблемы. - 2010. - Т. 13. - № 2. - С. 78-81

44. Зубарева А.М. Оценка пожарной опасности территории: на примере Еврейской автономной области: автореф. дис. ... канд. географ. наук. - Биробиджан, 2013. - 145 c.

45. Неуструев С.С. Элементы географии почв - М.; Л.: Сельхозгиз, 1930. $-240 \mathrm{c}$

46. Росликова В.И. Почвы Средне-Амурской низменности и их особенности агрогенных трансформаций // Вестник Тихоокеанского государственного университета. - 2009. - № 2 (13). C. $95-102$.

47. Стародумов А.М. Шкала пожарной опасности насаждений и других категорий площадей для условий Дальнего Востока. Хабаровск: ДальНИИЛХ, 1965. - 1 с.

48. Grassland fire spread simulation using NDVI / N.V. Baranovskiy, R.M. Kogan, V.A. Glagolev, A.M. Zubareva // 23rd International Symposium on Atmospheric and Ocean Optics. - Иркутск, 2017. URL: https://www.spiedigitallibrary.org/conference-proceedingsof-spie/10466/2286782/Grassland-fire-spread-simulation-usingNDVI-data/10.1117/12.2286782 (дата обращения 15.03.2021).

49. Исаченко А.Г. Методы прикладных ландшафтных исследований. - Л.: Наука, 1980. - 220 с.

50. Мирзеханова 3.Г., Нарбут Н.А. Методика расчёта потенциальной природной уязвимости территории. - Хабаровск: ИВЭП ДВО РАН, 1993. - 50 c.

51. Зубарева А.М., Фетисов Д.М. Комплексная оценка природной пожароопасности в Еврейской автономной области // География и природные ресурсы. - 2014. - № 4. - С. 138-145.

Поступила 12.04.2021 2.

\section{Информация об авторах}

Зубарева А.М., кандидат географических наук, научный сотрудник Института комплексного анализа региональных проблем ДВО РАН.

Зубарев В.А., кандидат биологических наук, научный сотрудник Института комплексного анализа региональных проблем ДВО РАН. 


\title{
UDK 630*432(571.621)
}

\section{COMPLEX EVALUATION OF POTENTIALLY NATURAL DRIED BOG-ASSOCIATED FIRE HAZARDS IN THE TERRITORY OF THE JEWISH AUTONOMOUS REGION}

\author{
Anna M. Zubareva ${ }^{1}$, \\ anna-doroshenko@yandex.ru
}

Vitaly A. Zubarev 1 , Zubarev_1986@mail.ru

1 Institute for Complex Analysis of Regional Problems of the Far East Branch of the Russian Academy of Sciences, 4, Sholem Aleichem street, Birobidzhan, 679016, Russia.

The relevance of the research was determined by the need to identify the most hazardous fire areas, prone to the effects of drainage. Identifying these areas forms the basis for predicting the risk of fires in addition to developing recommendations for the rational use and reduction of fire risks in the disturbed lands of the Jewish Autonomous Region.

The aim of the research is the comprehensive assessment of the potentially natural fire hazards associated with drained marshes in the Jewish Autonomous Region.

Methods. For a comprehensive assessment of the potentially natural fire hazards, the criteria were selected for medium shaped landscape with respect to occurrence of a fire: terrain (slope of the territory); climate (average annual rainfall and mean multiyear temperature in July); inland waters (density of the river network); soil (water permeability and soil moisture content); and vegetation (class of vegetationassociated fire dangers). Each indicator was evaluated on a uniform five-level scale. A comprehensive assessment was obtained by summing the scores, which were ranked according to the degree of fire hazard based on the developed scale.

Results. The authors have carried out the assessment, taking into account a number of the main natural factors causing the occurrence of fires within the wetlands. Areas with varying degrees of natural predisposition to the occurrence and spread of fires were identified. It was established that drainage reclamation is one of the agricultural factors contributing to the occurrence of vegetation fires. A change in the moisture regime primarily generates a transformation of the vegetation cover, where one type of vegetation is changed by another, as well as a change in soil cover and a decrease in the level of bog waters. All this leads to the fact that the class of fire hazard of the territory in aggregate and componentwise shifts towards an increase in fire hazard.

\section{Key words:}

Wildfire, drainage reclamation, comprehensive assessment, vegetation, bog water level.

\section{REFERENCES}

1. Hallema D.W., Robinne F.-N., Bladon K.D. Reframing the challenge of global wildfire threats to clean water. Earth's Future, 2018, vol. 6, no. 6, pp. 772-776.

2. Goldammer J.G. Regional climate change and forest fires. Large Area Forest Fires. Warsaw, Forest Research Institute, 2004. pp. 5-8.

3. Goldammer J.G. Report on early warning for fire and other environmental hazards. UN International Decade for Natural Disaster Reduction. Geneva, Freiburg University, 1997. pp. 3-34.

4. Frantz D., Stellmes M., Röder A., Hill J. Fire spread from MODIS burned area data: obtaining fire dynamics information for every single fire International. Journal of Wildland Fire, 2016, vol. 25 , no. 12 , pp. $1228-1237$.

5. Bedel A., Mote T., Goodrick S. Climate change and associated fire potential for the south-eastern United States in the 21st Century. International Journal of Wildland Fire, 2013, vol. 22, pp. 1034-1043.

6. Sychev R.S., Bazarov A.V., Badmaev N.B. The use of VEGA Science meteorological data to study differences in fire hazard occurrence in the Baikal region arid and humid landscapes. Sovremennye Problemy Distantsionnogo Zondirovaniya Zemli iz Kosmosa, 2020, vol. 17, no. 3, pp. 127-134. In Rus.

7. Kopoteva T.A., Kuptsova V.A. Effect of fires on the functioning of phytocenoses of peat bogs in the Middle-Amur lowland. Russian Journal of Ecology, 2016, vol. 47, no 1, pp. 11-18.

8. Dymov A.A., Abakumov E.V., Bezkorovaynaya I.N., Prokushkin A.S., Kuzyakov Ya.V., Milanovsky E.Yu. Impact of forest fire on soil properties (review). Theoretical and Applied Ecology, 2018, no. 4, pp. 13-23. In Rus.

9. Agus C., Ilfana Z.R., Azmi F.F., Rachmanadi D., Widiyatno, Wulandari D., Santosa P. B., Harun M.K., Yuwati T.W., Lestari T. The effect of tropical peat land-use changes on plant diversity and soil properties. International Journal of Environmental Science and Technology, 2020, vol. 17, pp. 1703-1712.

10. Depante M., Petrone R.M., Devito K.J., Kettridge N., Macrae M.L., Mendoza C., Waddington J.M. Potential influence of nutrient availability along a hillslope: Peatland gradient on aspen recovery following fire. Ecohydrology, 2018, vol. 11, no. 5. DOI: 10.1002/eco.1955.

11. Zumbrunnen T., Menéndez P., Bugmann H., Conedera M., Gimmi U., Bürgi M. Human impacts on fire occurrence: a case study of hundred years of forest fires in a dry alpine valley in Switzerland. Regional Environmental Change, 2012, vol. 12, no. 4 , pp. $935-949$.

12. Indrayanti L., Rotinsulu J.M., Yanarita Y., Sosilawaty S. Peat swamp forest; management and development of indigenous species to support economic local people at periphery foret (case study in Central Borneo, Indonesia). Journal of Ecological Engineering Received, 2019, vol. 20, no. 4, pp. 76-83.

13. Cattau M.E., Harrison M.E., Shinyo I., Tungau S., Uriart M., DeFries R. Sources of anthropogenic fire ignitions on the peat-swamp landscape in Kalimantan, Indonesia. Global Environmental Change, 2019, vol. 39, pp. 205-219.

14. Pinno B.D., Hawkes V.C. Temporal trends of ecosystem development on different site types in reclaimed boreal forests. Forests, 2015, vol. 6, no. 6, pp. 2109-2124.

15. Anderson J., Prescott C.E., Grayston S.J. Organic matter accumulation in reclaimed soils under spruce, poplar and grass in the Alberta Oil Sands. New Forests, 2019, vol. 50, pp. 307-322.

16. Kauffman J.B., Hernandez T.H., Del Carmen Jesus Garcia M., Contreras W.M. Carbon stocks of mangroves and losses arising from their conversion to cattle pastures in the Pantanos de Centla, Mexico. Wetlands Ecology and Management, 2016, vol. 24, pp. 203-216.

17. Priest J., Stovall J., Coble D., Oswald B., Williams H. Loblolly pine growth patterns on reclaimed mineland: allometry, biomass, and volume. Forests, 2015, vol. 6, no. 10, pp. 3547-3581.

18. Tremblay P.Y., Thiffault E., Pinno B.D. Effects of land reclamation practices on the productivity of young trembling aspen and white spruce on a reclaimed oil sands mining site in northern Alberta. New Forests, 2019, vol. 50, pp. 911-942. 
19. Gupta S.D., Pinno B.D. Spatial patterns and competition in trees in early successional reclaimed and natural boreal forests. Acta Oecologica, 2018, vol. 92, pp. 138-147.

20. Depante M., Morison M.Q., Petrone R.M., Devito K.J., Kettridge N., Waddington J.M. Hydraulic redistribution and hydrological controls on aspen transpiration and establishment in peatlands following wildfire. Hydrological Processes, 2019, vol. 33, no. 12 pp. 2714-2728.

21. Watts A.C., Kobziar L.N. Hydrology and fire regulate edge influence on microclimate in wetland forest patches. Freshwater Science, 2015. vol. 34, no. 4, pp. 1383-1393.

22. Sulwinski M., Metrak M., Suska-Malawska M. Long term fire effects of the drained open fen on organic soils. Archives of Environmental Protection, 2017, vol. 43, no. 1, pp. 11-19.

23. Begmatov I.A. Land meliorative status in irrigated lands of Syrdarya province. European Science Review, 2017, vol. 1-2, pp. $177-181$.

24. Kurbatsky N.P. Terminologiya lesnoy pirologii [Terminology of forest pyrology]. Voprosy lesnoy pirologii [Issues of forest pyrology]. Krasnoyarsk, IliD Publ., 1972. pp. 171-213.

25. Zubarev V.A. Change of concentrations of heavy metals in the components of a small river (on the example of drainage reclamation). Bulletin of the Tomsk Polytechnic University. Geo Assets Engineering, 2020, vol. 331, no. 8. pp. 16-23. In Rus.

26. Morison M.Q., Petrone R.M., Wilkinson S.L., Green A., Waddington J.M. Ecosystem scale evapotranspiration and $\mathrm{CO}_{2}$ exchange in burned and unburned peatlands: Implications for the ecohydrological resilience of carbon stocks to wildfire. Ecohydrology, 2020, vol. 13, no. 2, pp. 2189.

27. Nelson K., Thompson D., Hopkinson C., Petrone R., Chasmer L. Peatland-fire interactions: a review of wildland fire feedbacks and interactions in Canadian boreal peatlands. Science of the Total Environment, 2021, vol. 769, pp. 145212

28. Vadrevu K.P., Lasko K., Giglio L., Schroeder W., Biswas S., Justice C. Trends in vegetation fires in south and south-east Asian countries. Scientific Reports, 2019, vol. 9, no. 7422, pp. 1-13.

29. Erni S., Arseneault D., Parisien M.A., Begin Y. Spatial and temporal dimensions of fire activity in the fire-prone eastern Canadian taiga. Global Change Biology, 2017, vol. 23, no. 3, pp 1152-1166.

30. Gu H., Zheng W., Xu D., Mu C. Short-term effects of fire disturbance on $\mathrm{CH}_{4}$ emission from forested wetlands in the Xiaoxing'an Mountains, Northeast China. Journal of Forestry Research, 2019, vol. 30, pp. 969-979.

31. Vetrita Y., Cochrane M.A. Fire frequency and related land-use and land-cover changes in Indonesia's Peatlands. Remote Sens, 2020 vol. 12 , no. 1 , pp. 5-11

32. Jancoski H.S., Pinto J.R.R., Nogueira D.S., Mews H.A., Abad J.S., Scalon M.C., Marimon B.S. Fine-scale effects of fire on nonwoody species in a southern Amazonian seasonal wetland. Wetlands Ecology and Management, 2019, vol. 27, pp. 267-281.

33. Mustaphi C.J.C., Kinyanjui R., Shoemaker A., Mumbi C., Muiruri V., Marchant L., Rucina S.M., Marchant R. A 3000-year record of vegetation changes and fire at a high-elevation wetland on Kilimanjaro, Tanzania. Quaternary Research, 2020, vol. 99, pp. 34-62.

34. Sinyutkina A.A., Burnashova E.N., Belenko A.A., Gashkova L.P. Maloletko A.A. Assessment of potential fire risk of Tomsk region mires. Bulletin of the Tomsk Polytechnic University. Geo Assets Engineering, 2015, vol. 326, no. 12. pp. 45-53. In Rus.

35. Bezpalko R.V. Vliyanie osusheniya na prirodnuyu pozharnuyu opasnost lesov. Avtoreferat Dis. Kand. nauk [The influence of drainage on the natural fire hazard of forests. Cand. Diss. Abstract] St-Petersburg, 2004. 27 p.
36. Kurentsova G.E. Ocherk rastitelnosti Evreyskoy avtonomnoy oblasti [An outline of the vegetation of the Jewish Autonomous Region]. Vladivostok, Far Eastern Book Publ., 1967. 61 p.

37. Zubarev V.A., Mishchuk S.N Changes in concentration of heavy metals in soils of Middle Amur lowland under conditions of long period of agricultural use. Bulletin of the Tomsk Polytechnic University. Geo Assets Engineering, 2019, vol. 330, no. 8, pp. 18-26. In Rus.

38. Zubarev V.A., Kogan R.M. Ecological conditions of watercourses in the Middle Amur Lowland in the areas of drainage reclamation. Water Resources, 2017, vol. 44, no. 7, pp. 940-951.

39. Zubarev V.A., Mazhaysky Y.A., Guseva T.M. The impact of drainage reclamation on the components of agricultural landscapes of small rivers. Agronomy Research, 2020, vol. 18, no. 4, pp. 2677-2686.

40. Arcybashev E.S. The problem of fires on peat forest lands. Lesnoe khozyaystvo, 2006, vol. 5, pp. 36-38. In Rus.

41. Sheshukov M.A. Issledovanie prirody nizovykh pozharov v osnovnykh lesnykh formatsiyakh Nizhnego Priamurya. Avtoreferat Dis. Kand. nauk [Investigation of the nature of ground fires in the main forest formations of the Lower Amur region. Cand. Diss. Abstract] Krasnoyarsk, 1970. 27 p.

42. Kogan R. M, Glagolev V.A. System of spatial forecast of fires emergence on weather and forest vegetation conditions. Safety in Technosphere, vol. 2, no. 5, pp. 11-20. In Rus.

43. Grigor'eva E.A., Kogan R.M. Pyro-logical characteristics of climate in the south of the Russian Far East. Regional problems, 2010, vol. 13, no. 2, pp. 78-82. In Rus.

44. Zubareva A.M. Otsenka pozharnoy opasnosti territorii: na primere Evreyskoy avtonomnoy oblasti. Avtoreferat Dis. Kand. nauk [Assessment of the fire hazard of the territory: on the example of the Jewish Autonomous Region. Dis. Cand. Abstract]. Birobidzhan, 2013. $145 \mathrm{p}$.

45. Neustruev S.S. Elementy geografii pochv [Elements of soil geography]. Moscow, Leningrad, Selkhozgiz Publ., 1930. 240 p.

46. Roslikova V.I. Soils of the Middle-Amur Lowland and features of their agrogenic transformations. Bulletin of Pacific national university, 2009, vol. 2, no. 13, pp. 95-102. In Rus.

47. Starodumov A.M. Shkala pozharnoy opasnosti nasazhdeniy i drugijh kategoriy ploshchadey dlya usloviy Dalnego Vostoka [Scale of fire hazard of plantings and other categories of areas for the conditions of the Far East]. Khabarovsk, DalNIILH Publ., 1965. $1 \mathrm{p}$

48. Baranovskiy N.V., Kogan R.M., Glagolev V.A., Zubareva A.M. Grassland fire spread simulation using NDVI. 23rd International Symposium on Atmospheric and Ocean Optics. Irkutsk, 2017. Available at: https://www.spiedigitallibrary.org/conferenceproceedings-of-spie/10466/2286782/Grassland-fire-spreadsimulation-using-NDVI-data/10.1117/12.2286782 (accessed 15 March 2021).

49. Isachenko A.G. Metody prikladnykh landshaftnykh issledovaniy [Methods of applied landscape research]. Leningrad, Nauka Publ., 1980. $220 \mathrm{p}$

50. Mirzekhanova Z.G., Narbut N.A. Metodika rascheta potentsialnoy prirodnoy uyazvimosti territorii [Methodology for calculating the potential natural vulnerability of the territory]. Khabarovsk, IVEP DVO RAN Publ., 1993. $50 \mathrm{p}$

51. Zubareva A.M., Fetisov D.M. Comprehensive assessment of natural fire hazard in Jewish Autonomous Oblast. Geography and Natural Resources, 2014, no. 4, pp. 138-145. In Rus.

Received: 12 April 2021.

\section{Information about the authors}

Anna M. Zubareva, Cand. Sc, researcher, Institute for Complex Analysis of Regional Problems of the Far East Branch of the Russian Academy of Sciences.

Vitaly A. Zubarev, Cand. Sc, researcher, Institute for Complex Analysis of Regional Problems of the Far East Branch of the Russian Academy of Sciences. 